\title{
Is the use of gonadotrophin-releasing hormone agonists facilitates vaginal hysterectomy in moderate enlarged uterus?
}

\author{
Mohamed AbdElzaher, ${ }^{\text {a,d }}$ Ashraf Moawad,,${ }^{\text {a,e }}$ Mohamed Ali, ${ }^{\text {a }}$ Wael A. Ismail \\ Madkour, ${ }^{b}$ and Hena Zaheer, M.D. ${ }^{\text {d }}$ \\ ${ }^{a}$ Obstetrics and Gynecology department (Al-Azhar University, Cairo, Egypt), ${ }^{\mathrm{b}}$ Obstetrics \\ and Gynecology department (Ain-Shams University, Cairo, Egypt) ${ }^{c}$ Obstetrics and \\ Gynecology department (Shadan Medical College, India), ${ }^{d}$ Salman bin-abdulaziz University,

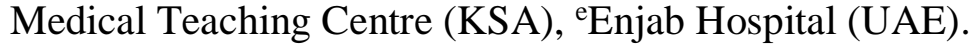

\begin{abstract}
Introduction: Vaginal hysterectomy is considered to be the method of choice for removal of the uterus but most gynecologists still prefer the abdominal route for removal of benign large uteri $>14$ weeks. GnRH agonists such as goserelin can reduce uterine bulk by up to $60 \%$ and was initially used to convert a midline to Pfannenstiel incision in abdominal hysterectomy. The conversion of an abdominal to a potential vaginal hysterectomy by uterine size reduction would prove advantageous.
\end{abstract}

Objective: To evaluate the efficacy of the preoperative administration of GnRH agonist for women with enlarged uteri without prolapse in order to facilitate vaginal hysterectomy; in comparison with patients with enlarged uteri who underwent to direct Total abdominal hysterectomy for a similar indication (i.e. Menorrhagia).

Design: Prospective multicentre randomized controlled trial

Setting: Tertiary Center Hospitals

Methods: Women scheduled for hysterectomy for menorrhagia with non-prolapsing clinical uterine size of $>14$ weeks were offered an attempt for vaginal hysterectomy after pre-treatment with Goserelin for 3 months (Study group= 30). A group of women with comparable uterine size who underwent abdominal hysterectomy for similar indication served as (Control group=30). Pre- and postoperative data such as hemoglobin, myoma size, uterine weight, duration of procedure and complications, pain score, and length of hospital stay were collected prospectively.

Results: Both groups had comparable preoperative hemoglobin, body mass index and subjective preoperative uterine bulk ( $16.7 \pm 2.4$ vs $16.9 \pm 2.2$ weeks). The uterine weight was lower in the study group $(507.6 \pm 211 \mathrm{~g}$ ) compared to the control group $(728.8 \pm 189 \mathrm{~g}), \mathrm{P}<0.001$. The subjective mean decrease in clinical uterine bulk was $20 \%$. The duration of surgery was nearly twice as long in vaginal $(123.3 \pm 34.9 \mathrm{~min})$ compared to abdominal hysterectomy $(73.9 \pm 23.9 \mathrm{~min}), \mathrm{P}<0.001$, but analgesia use and the length of inpatient stay were lower in the study group (2.4 \pm 1 days) compared to control group (4.97 \pm 1.5 days), $\mathrm{P}<0.001$. No significant difference between the two groups as regards the rate of occurrence of surgical complications.

Conclusions: In women with $>14$ week size uteri, treatment with gonadotrophin agonists reduces uterine size sufficiently to allow safe vaginal hysterectomy. Although duration of surgery was longer, women who underwent vaginal hysterectomy required less analgesia and had shorter inpatient stay.

Keywords: Non-descent vaginal hysterectomy, Gonadotrophin-releasing hormone agonist. 


\section{Introduction}

In the US, over 600,000 hysterectomies are performed annually, making it second only to cesarean delivery among surgeries performed on women (Wu et al. 2007). The abdominal approach, the most commonly performed (Whiteman et al. 2008), carries the highest complication rate (Garry et al. 2004) and imposes the greatest recovery burden and highest cost (Lumsden et al 2000).

Laparoscopic hysterectomy, potentially a less invasive alternative to abdominal hysterectomy, has suffered from slow skill development (Reich and Robert 2003) and higher complication rates (Altgassen et al. 2004) and cost as compared to the vaginal approach (Kovac 2000).

Vaginal hysterectomy, with its lowest rate of complications, recovery burden, and costs (Van Den et al.1998), (Mulholland et al. 1996), might be considered the optimal approach. Mindful, the American College of Obstetricians and Gynecologists, in its November 2009 Committee Opinion regarding hysterectomy route for benign indications states, "evidence demonstrates that, in general, vaginal hysterectomy is associated with better outcomes and fewer complications than laparoscopic or abdominal hysterectomy" concluding "vaginal hysterectomy is the approach of choice whenever feasible, based on its well-documented advantages and lower complication rates" (ACOG Committee Opinion 2009).

The most common reason cited by gynecologists for favoring abdominal over the vaginal approach is large uterine bulk, and many would be reluctant to attempt $\mathrm{VH}$ in patients with an estimated uterine size of $12-$ 14 weeks (Doucette et al. 2001), (Synder et al. 2002). Observational and comparative studies by (Magos et al. 1996), (Harmanli et al. 2004) and (Sahin 2007). However, demonstrated that uteri of up to 20 weeks could be removed vaginally.

GnRH agonists induce a profound down regulation of the pituitary with a subsequent post receptor message blockage for gonadotropin synthesis and secretion. After a rapid secretion of gonadotropins ("flare-up" effect) during the first 2 weeks of treatment, there is a weak inhibition of pituitary function with inhibition of follicular development, anovulation, and a reversible hypogonadotropic hypogonadism state (Filicori et al.1983), (Brosens 1997).

There are several protocols for analog administration (Pickersgill 1998). GnRH usually administered in the early follicular phase (day 2-3 of the menstrual cycle). They are used preoperatively for 2 or 3 months in short-term protocols both to reduce fibroid and uterine volume and to control bleeding, whereas long-term protocols (over 6 months) are used in perimenopausal women to induce an iatrogenic climacteric state in the long-term nonsurgical management of symptomatic leiomyomas (Pickersgill 1998).

Stovall and colleagues have used gonadotrophin-releasing hormone (GnRH) agonists as a preoperative adjunct to medically debulk uteri, thus enabling hysterectomy, which otherwise would have been approached abdominally, to be performed vaginally (Stovall et al. 1994).

In this study, our purpose was to evaluate the efficacy of the preoperative administration of a GnRH agonist for women with enlarged uteri without prolapse in order to facilitate vaginal hysterectomy; the control group comprised patients with enlarged uteri who underwent to direct total abdominal hysterectomy (TAH) for a similar indication (i.e. menorrhagia).

\section{Patients and methods}

\section{Subjects:}

This is a prospective study which was carried out at the Obstetrics and Gynecology departments of 3 tertiary hospitals (Medical Teaching Centre- KSA and Enjab HospitalUAE -Bab El sharia hospital CE) during the period from June 2008 to December 2011. The study was approved by the Ethics Committee of all hospitals. Sixty women admitted for hysterectomy for menorrhagia were participated in the study and enrolled after informed and written consent. Inclusion criteria included uterine size $\geq 14$ not exceeding 20 weeks of gravid uterus (by clinical judgment), adequate access with good uterine mobility. Exclusion criteria included uterus with severely restricted mobility, women with vaginas narrower than two fingers, wide suspicion of malignancy, 
extensive pelvic adhesion and complex adnexal mass.

\section{Randomization and Preparation:}

Patients who participated in the study were randomized either to vaginal hysterectomy after preoperative administration goserelin acetate $3.6 \mathrm{mg}$ (Zoladex, Astra Zeneca, Ltd.) intramuscular every 4 weeks for 3 doses, treatment was started on day 2 of menstrual cycle. (Study group $=30$ ) or to direct TAH (control group $=30)$. Randomization was performed using a list of computer-generated random numbers and participants were assigned to their groups using sealed envelopes.

Detailed history and clinical examinations were done in each case. Women had preoperative clinical evaluation of uterine size and mobility, pelvic Ultrasonography, and when indicated diagnostic hysteroscopy and endometrial sampling. Patients were followed every 4 weeks for the treatment duration. During treatment each patient underwent monthly pelvic examination by the same physician and repeat sonography to determine uterine and fibroid volume. The baseline characteristics of the patients including age, body mass index, obstetric history, menopause, previous surgery, and preoperative diagnosis were recorded at admission.

\section{Surgery and post-operative follow up:}

Each subject received prophylactic antibiotic treatment (cefazoline $2 \mathrm{~g}$ intravenously) at the beginning of the operation and prophylactic anticoagulant therapy with low molecular weight heparin the evening before the operation, wore anti embolic stockings and/or sequential compression stockings. All operations were performed by Consultants. $\mathrm{VH}$ patients had a vaginal pack and indwelling urinary catheter in situ until the following morning. In addition, operative time, uterine weight, estimated blood loss, perioperative and postoperative complications, pain score, and length of hospital stay were also recorded before discharge. The operative time was calculated from the first incision to the end of wound closure.

Blood loss was estimated by summation of the blood volume aspirated and the weight difference of the gauze used before and after surgery. If a blood transfusion was performed, the number of transfused blood was recorded.
At the end of the surgery, the extirpated uteri were weighed before fixation in formalin. Pain was evaluated using the visual analog scoring (VAS) system: 0 no pain, 2 mild pain, 5 moderate pain, 7 severe pain, 10 excruciating (Fishman et al. 1987). VAS is recorded every $6 \mathrm{~h}$ by the nursing staff. The highest VAS on postoperative day 0 and postoperative day 1 was used. All patients received a standardized postoperative protocol of two doses of $50 \mathrm{mg}$ of meperidine intravenously $4 \mathrm{~h}$ apart for pain control, followed by $500 \mathrm{mg}$ acetaminophen every $6 \mathrm{~h}$. The complications analyzed were as follows: (1) major: injury to a major blood vessel or organ (i.e., bowel, bladder, or ureter), hematoma or bleeding of the vaginal cuff requiring prolongation of care or surgical treatment or (2) minor: febrile morbidity (defined as two or more oral temperatures ${ }_{3} 38^{\circ} \mathrm{C}$ occurring more than $6 \mathrm{~h}$ apart excluding first $24 \mathrm{~h}$ ), vaginal cuff infection, vaginal cuff hematoma, pelvic infection, or urinary tract infection. Unintended conversion to TAH was also noted.

Outcome measures for both the groups were studied comparatively in terms of length of operative time, amount of blood loss, requirement of blood transfusion, perioperative and postoperative complications, pain score, and length of hospital stay.

\section{Data registration and Statistical analysis:}

The results were tabulated and statistically analyzed using a computer program SPSS (statistic a package for social science), version 15 software. The sample mean (X), standard deviation (SD), and standard error of the mean as well as the range were obtained for numerical variables. For non-numerical variables, the frequency, distribution and percentage were calculated. The student's (t) test was used to test the significance of the difference between 2 independent means.

The Chi square test $\left(X^{2}\right)$ was used to test whether the distribution of a certain phenomenon among two or more groups was equal or not. The probability $(\mathrm{P})$ value was calculated and a P-value $<0.05$ was considered statistically significant.

\section{Results}

This study was performed in the period from June 2008 to December 2011. Two hundred 
and forty women underwent hysterectomy during the study period and only 60 patients were eligible to enroll in the study. Patients were divided into two groups, vaginal hysterectomy after preoperative administration GnRH a (study group $=30$ ) and direct $\mathrm{TAH}$ (control group $=30$ ).
Table 1. shows the basic clinical characteristics of the patients in both groups. There was no significant difference in terms of age, parity, body mass index, Clinical size of uterus, previous cesarean delivery, or previous pelvic surgery.

Table 1: Patient characteristics

\begin{tabular}{|l|c|c|c|}
\hline Patient characteristics & VH $(\mathbf{n}=\mathbf{3 0})$ & TAH $(\mathbf{n}=\mathbf{3 0})$ & P value \\
\hline Age, years & $48.7 \pm 3.7$ & $50.3 \pm 4.3$ & 0.116 \\
\hline Parity & $3.9 \pm 1.8$ & $4.7 \pm 2.1$ & 0.102 \\
\hline Body mass index, $\mathbf{~ k g ~} \mathbf{~ m}^{\mathbf{2}}$ & $31.1 \pm 2.2$ & $29.7 \pm 5.6$ & 0.199 \\
\hline $\begin{array}{l}\text { Clinical size of uterus } \\
\text { (weeks) }\end{array}$ & $16.7 \pm 2.4$ & $16.9 \pm 2.2$ & 0.176 \\
\hline Previous cesarean section & $2(6.7 \%)$ & $3(10 \%)$ & 1.00 \\
\hline Previous abdominal surgery & $1(3.4 \%)$ & $2(6.7 \%)$ & 1.00 \\
\hline
\end{tabular}

Surgical characteristics are presented in Table 2. The mean subjective uterine size of the VH group prior to Goserelin injections was $(16.7 \pm 2.4$ weeks $)$ compared to $(16.9 \pm 2.2$ weeks) in TAH group. On the other hand, the subjective uterine bulk at the time of surgery was $(14.07 \pm 1.4$ weeks $)$ in $\mathrm{VH}$ group vs. (16.9 \pm 2.2 weeks) in TAH group and uterine weight was $(507.6 \pm 211 \mathrm{~g})$ in VH group vs. $(728.8 \pm 189 \mathrm{~g})$ in $\mathrm{TAH}$ group; which were comparable in both groups $(\mathrm{p}<0.001$ for each variable). The subjective mean decrease in clinical uterine bulk was $20 \%$.

The mean duration of surgery $(123.3 \pm 34.9$ vs. $73.9 \pm 23.9 \mathrm{~min}) \quad(\mathrm{p}<0.001)$ and estimated blood loss $(485.4 \pm 196.8$ vs. $366.5 \pm 176.4 \mathrm{ml})$ $(p<0.05)$ were significantly higher in the vaginal compared to the abdominal hysterectomy group. Four women in VH group sustained a blood loss in excess of $500 \mathrm{ml}$, three of them need blood transfusion, and by comparison, one woman in TAH group sustained a blood loss in excess of $500 \mathrm{ml}$ and no need blood transfusion $(\mathrm{P}>0.05)$. Salpingo-oophorectomy was performed in two patients $(6.7 \%)$ in $\mathrm{VH}$ group and 3 patients (10\%) TAH group $(\mathrm{P}=1.00)$.

The mean length of hospital stay $(2.4 \pm 1$ vs $4.97 \pm 1.5$ days $)(p<0.001)$ were significantly lower in the vaginal compared to the abdominal hysterectomy group. Mean pain score in postoperative day0 was $(2.6 \pm 1.8$ vs. 5.6 \pm 2.6$)$ and in postoperative day1 $(1.5 \pm 1.5$ vs. $3.1 \pm 1.5)(\mathrm{P}<0.001$ for each variables $)$.

Table 2: Surgical characteristics

\begin{tabular}{|l|c|c|c|}
\hline & VH (n=30) & TAH (n= 30) & P value \\
\hline $\begin{array}{l}\text { Clinical size at time of surgery } \\
\text { (wk) }\end{array}$ & $14.07 \pm 1.4$ & $16.9 \pm 2.2$ & 0.001 \\
\hline Histological uterine weight $\mathbf{( g )}$ & $507.6 \pm 211$ & $728.8 \pm 189$ & 0.001 \\
\hline Operating time (min) & $123.3 \pm 34.9$ & $73.9 \pm 23.9$ & 0.001 \\
\hline Estimated blood loss ( ml) & $485.4 \pm 196.8$ & $366.5 \pm 176.4$ & 0.017 \\
\hline Blood loss > 500 ml & $4(13.4 \%)$ & $1(3.4 \%)$ & 0.353 \\
\hline Blood transfusion (n \& \%) & $3(10 \%)$ & $0(0 \%)$ & 0.237 \\
\hline $\begin{array}{l}\text { Bilateral salpingo- } \\
\text { oophorectomy (n \& \%) }\end{array}$ & $2(6.7 \%)$ & $3(10 \%)$ & 1.00 \\
\hline Length of stay (days) & & & 0.001 \\
\hline Pain, day 0 & $2.4 \pm 1$ & $4.97 \pm 1.5$ & 0.001 \\
\hline Pain, day 1 & $2.6 \pm 1.8$ & $5.6 \pm 2.6$ & 0.001 \\
\hline Total complication (n \& \%) & $1.5 \pm 1.5$ & $3.1 \pm 1.5$ & 0.360 \\
\hline
\end{tabular}


Operative and postoperative complications are presented in Table 3. No significant difference was noted in overall complications between groups $(\mathrm{P}=0.36)$. One patient in $\mathrm{VH}$ group sustained a bladder injury; this patient had one previous caesarean section. The injury was recognized during the operation and treated by trans-vaginal route with good outcome. There was no bowel or ureteral injury. There was no reopening or conversion to laparotomy, or surgical mortality. All patients were followed up at our hospital for at least 3 months after surgery and all recovered uneventfully.

Table 3: Complications

\begin{tabular}{|l|c|c|c|}
\hline & VH (n=30) & TAH (n= 30) & P value \\
\hline Major complications (n) & \multicolumn{3}{|c|}{} \\
\hline Bladder injury & $1(3.4 \%)$ & - & 1.00 \\
\hline Major vessel injury & - & $1(3.4 \%)$ & 1.00 \\
\hline Minor complications (n) & \multicolumn{3}{|l|}{} \\
\hline $\begin{array}{l}\text { Vaginal cuff hematoma or } \\
\text { infection }\end{array}$ & $2(6.7 \%)$ & $1(3.4 \%)$ & 1.00 \\
\hline Urinary tract infection & - & $2(6.7 \%)$ & 0.492 \\
\hline Febrile morbidity & $1(3.4 \%)$ & $2(6.7 \%)$ & 1.00 \\
\hline Ileus & $1(3.4 \%)$ & $2(6.7 \%)$ & 1.00 \\
\hline Respiratory infection & - & $1(3.4 \%)$ & 1.00 \\
\hline
\end{tabular}

\section{Discussion}

It is a well-known fact that $70 \%$ to $80 \%$ of hysterectomies are performed by abdominal route and vaginal approach is usually reserved for uterovaginal prolapse (Thomas 2007).

The usual contraindications for vaginal hysterectomy are absence of significant uterovaginal prolapse, presence of uterine enlargement, adhesions and the need for oophorectomy. With adequate vaginal access and good uterine mobility, vaginal hysterectomy can be easily performed.

The uterosacral and cardinal ligaments, situated in close proximity to the vaginal vault once clamped and cut produce first degree descent. Multiparty, lax tissues following multiple deliveries and decreased tissue tensile strength provide comfort to vaginal surgeon even in the presence of uterine enlargement. The other important reason for the lower proportion of hysterectomies performed vaginally is the presence of uterine enlargement with leiomyomas or adenomyosis.

Hysterectomy remains one of the commonest gynecological operations, and the Cochrane review on the subject (Nieboer et al. 2009) concluded (on the basis of safety, reduced postoperative pain, shortened length of stay and higher patient satisfaction) that $\mathrm{VH}$ should be performed in preference to TAH, and if not possible, then a laparoscopically assisted approach may then be used.

Furthermore, both Reich and Garry, pioneers of laparoscopic hysterectomy, agreed that "evidence based studies support the use of vaginal hysterectomy if possible over laparoscopic and abdominal hysterectomy" (Reich H 2007), (Garry R 2009).

Despite this, there is still reluctance for gynecologists to perform $\mathrm{VH}$, even in the absence of prolapse and when the uterine size exceeds 12 weeks. In fact, only $15 \%$ of hysterectomies for fibroids in the US (Lepine et al. 1997) were performed vaginally, although many authors have now reported successful vaginal removal of enlarged uteri of up to 20 weeks (Magos et al. 1996), (Sahin 2007) using techniques such as bisection, Lash intramyometrial coring, vaginal myomectomy, wedge resection and debulking.

The ACOG guidelines for hysterectomy route state that the choice "depends on the patient's anatomy and the surgeon's experience" and it is usually done in women with mobile uteri no larger than one at 12 weeks' gestation $(280 \mathrm{~g})$ (American College of Obstetricians and Gynecologists 1989).

Indications for abdominal hysterectomy are usually determined from the standard surgical text (Thompson 1992). Those indications include uterine size larger than $280 \mathrm{~g}$, previous pelvic surgery, and history of pelvic inflammatory disease, endometriosis, 
concomitant adnexal masses, and indication for adnexectomy. However, (Kovac 1995) was able to do vaginal hysterectomies in $97 \%$ of women who had those presumptive risk factors that are believed to mandate abdominal hysterectomy.

$\mathrm{GnRH}$ agonist treatment is known to reduce the volume of uterus by $35-50 \%$. The reduction in myoma size is reported as a wide range (15-90\%) with reduction in blood flow through the uterine vessels after GnRH agonist therapy (Broekmans 1996), (Stovall et al. 1994) were the first to describe the concept of medically debulking the enlarged uterus to facilitate $\mathrm{VH}$ and were able to show a success rate of $70 \%$ for uteri between 14 and 18 weeks.

When translated in to cost analyses, significant potential savings could be made, which would easily compensate for the cost of preoperative $\mathrm{GnRH}$ analogues expenditure (Bradham et al. 1995). Previous costing by Johns et al from the US (Pickersgill 1998) indicated that the average hospital charge for VH was US $\$ 700$ less than TAH (US $\$ 5,869$ vs. $\$ 6,552$ ) but more net profit with the former because of the shorter duration of inpatient stay.

While laparoscopy is a useful adjunct to $\mathrm{VH}$ when extensive adhesiolysis is contemplated or when there is suspected adnexal pathology, we concur with previous authors (Magos et al. 1996), (Unger 1999), (Varma et al. 2001) that laparoscopic assistance is not otherwise necessary for the vaginal removal of a moderately enlarged uterus.

Our study simply seeks to suggest that medical debulking using GnRH analogues can convert an abdominal to a potentially safe $\mathrm{VH}$ and is a simple and cost-effective way through which "average" gynecologists can improve skill and confidence in attempting the vaginal route.

Our study corroborates the previous findings that the neoadjuvant use of GnRH analogues can help facilitate vaginal hysterectomies in moderately large uteri and further demonstrates positive advantages compared to a group of patients with similar uterine size at surgery that underwent TAH.

The mean weight of uteri removed in the present study was high above the limit of 280 $\mathrm{g}$ (12 weeks' gestation) that was recommended as the limit for vaginal hysterectomy (American College of Obstetricians and Gynecologists 1989), (Kovac 1995). In most of cases the uterine weight was at least $500 \mathrm{~g}$ with no special difficulties.

Therefore, as (Magos et al. 1996) concluded, uterine size by itself should no longer be considered a contraindication to vaginal hysterectomy. As reported (Unger JB 1999), (Richardson et al. 1995) previous pelvic surgery, mild endometriosis, history of pelvic inflammatory disease, or uterine fibroids should no longer be regarded as contraindications for vaginal surgery.

In the present study, the mean duration of surgery and estimated blood loss were significantly higher in the vaginal compared to the abdominal hysterectomy group $(\mathrm{p}<0.001$, $\mathrm{p}<0.05)$ also the mean length of hospital stay and mean pain score in postoperative days were significantly lower in the vaginal compared to the abdominal hysterectomy group ( $p<0.001$ ). (Joan et al. 2011) resorted to this technique and reported similar findings.

We were successful in removing uteri of up to 20 weeks pregnancy size vaginally without any increase in surgical complications. Similar findings were reported by Unger (Unger 1999) who operated upon uteri weighing 200 to $700 \mathrm{gm}$, without any increase in complications as compared to abdominal hysterectomies.

The current study shows no significant difference between the two groups as regards the rate of occurrence of surgical complications. The length of hospital stay reported by (Dorsey et al. 1995) was 3.5 versus 4.5 days for total vaginal and total abdominal hysterectomy respectively. In our study hospital stay was 2.4 versus 4.9 days for total vaginal and total abdominal hysterectomy respectively.

In conclusion, the preoperative administration of a GnRH agonist to facilitate vaginal hysterectomy in women with non-descent and moderately enlarged uteri is safe and efficient. With experience, operative time, blood loss and complications can be reduced considerably. Thus this vaginal approach should be chosen as a preferred method of hysterectomy. 


\section{References}

ACOG Committee Opinion, 2009 :Choosing the route of hysterectomy for benign disease .Obstet Gyneco;, 114(5):1156-1158,.

Altgassen C, Michels W, Schneider A, 2004: Learning laparoscopic-assisted hysterectomy. Obstet Gynec; 104(2):308-313,

American College of Obstetricians and Gynecologists, 1989: Quality assurance in obstetrics and gynecology. Washington, DC: American College of Obstetricians and Gynecologists,.

Bradham DD, Stovall TG, Thompson CD,1995: Use of GnRH agonist before hysterectomy: a cost simulation. Obstet Gynecol;85( 3 ):401-406.

Broekmans FJ,1996: GnRH agonists and uterine leiomyomas. Hum Reprod; 11 ( 3):3-25.

Brosens TA, 1997: Variable response of uterine leiomyomas after GnRH agonist therapy. Fertil Steril; 68(5):948-949.

Dorsey JH, Steinberg EP, Holtz PM, 1995: Clinical indications for hysterectomy route: patient haracteristics or physician preference?Am J Obstet Gynecol;173(5):1452-1460

Doucette RC, Sharp HT, Alder SC, 2001: Challenging generally accepted contraindications to vaginal hysterectomy. Am J Obstet Gynecol;184(7):1386-1389.

Filicori M, Hall DA, Loughlin JS, Rivier J, Vale W, Crowley WF Jr,1983: A conservative approach to the management of uterine leiomyoma: pituitary desensibilization by a luteinizing hormone-releasing hormone analogue. Am J Obstet Gynecol; 147:726-727.

Fishman B, Pasternak S, Wallenstein SL, Houde RW, Holland JC, Foley KM,1987: The Memorial Pain Assessment Card. A valid instrument for the evaluation of cancer pain. Cancer, 60(5):11511158.

Garry R,2009: The best way to determine the best way to undertake a hysterectomy. BJOG; 116(4):473-476.

Garry R, Fountain J, Mason S, Hawe J, Napp V, Abbott J, Clayton R, Phillips G, Whittaker M, Lilford R, 2004: The eVALuate study: two parallel randomised trials, one comparing laparoscopic with abdominal hysterectomy, the other comparing laparoscopic with vaginal hysterectomy. BMJ; 328(7432):129-138.

Harmanli OH, Gentzler CK, Byun S, Dandolu MH, Grody T,2004: A comparison of abdominal and vaginal hysterectomy for the large uterus. Int $\mathbf{J}$ Gynaecol Obstet;87(1):19-23.

Joan M, Ravi B, Abiodun F, Wai Y,2011: Medical debulking with gonadotrophin-releasing hormone agonists to facilitate vaginal hysterectomy. Gynecol Surg;9(1):77-80.
Kovac RS,1995: Guidelines to determine the route of hysterectomy. Obstet Gynecol; 85(1):18-23.

Kovac SR, 2000: Hysterectomy outcomes in patients with similar indications. Obstet Gynecol; 95(6 Pt 1):787-793.

Lepine LA, Hillis SD, Marchbanks PA, Koonin LM, Morrow B, Kieke BA, 1997: Hysterectomy surveillance-United States 1980-93. CDC Surveillance summaries, August 8, 1997. MMWR Morb Mortal Wkly Rep; 46(SS4): 1-15.

Lumsden MA TS, Hawthorn R, Traynor I, Gilmore D, Davis J, 2000: A randomised comparison and economic evaluation of laparoscopic-assisted hysterectomy and abdominal hysterectomy. BJOG; 53:214-219

Magos A, Bournas N, Sinha R, Richardson RE, O'Connor H , 1996 : Vaginal hysterectomy for the large uterus. BJOG; 103(3):246-251.

Mulholland C, Harding N, Bradley S, Stevenson M, 1996: Regional variations in the utilization rate of vaginal and abdominal hysterectomies in the United Kingdom. J Public Health Med; 18(4):400405.

Nieboer TE, Johnson N, Lethaby A, Tavender E, Curr E, Garry R, van Voorst S, Mol BW, Kluivers KB, 2009: Surgical approach to hysterectomy for benign gynaecological disease. Cochrane Database Syst Rev (3):CD003677.

Pickersgill A, 1998 : GnRH agonists and addback therapy: is there a perfect combination ? $\mathrm{Br} \mathrm{J}$ Obstet Gynaecol; 105: 475-485.

Reich H, 2007: Total laparoscopic hysterectomy indications, techniques and outcomes. Curr Opin Obstet Gyneco;19(4):337-344.

Reich H, Robert L, 2003: Laparoscopic hysterectomy in current gynaecological practice. Rev Gynaecol Pract; 3:32-40.

Richardson R, Bournas N, Magos A, 1995: Is laparoscopic hysterectomy a waste of time? Lancet, 345:36-41.

Sahin Y, 2007: Vaginal hysterectomy and oophorectomy in women with 12-20 weeks' size uterus. Acta Obstet Gynecol Scand; 86(11):13591369.

Stovall TG, Summit RL Jr, Washburn SA, Ling FW, 1994: Gonadotropin-releasing hormone agonist use before hysterectomy.Am J Obstet Gynecol ; 170(6):1744-1748.

Synder TE, Stovall TG, 2002: Use of gonadotrophin releasing hormone agonist before hysterectomy.In: Sheth S, Studd J (eds) Vaginal hysterectomy Martin Dunitz, London, Chapter 10:pp 111-127.

Thompson JD, 1992: Hysterectomy. In: Thompson JD, Rock JA, eds. Te Linde's operative gynecology. Philadelphia: JB Lippincott, 663-738. Thomas G.Stovall,2007: Hysterectomy: Berek \& 
Is the use of gonadotrophin...

Novak's Gynecology14th Edition, 22 (c): $805 .$.

Unger JB, 1999: Vaginal hysterectomy for the woman with a moderately enlarged uterus weighing 200 to 700 grams. Am J Obstet Gynecol; 180(6 Pt 1):1337-1344.

Van Den Eeden SK, Glasser M, Mathias SD, Colwell HH, Pasta DJ, Kunz K, 1998: Quality of life, health care utilization, and costs among women undergoing hysterectomy in a managedcare setting. Am J Obstet Gynecol; 178:91-100.

Varma R, Tahseen S, Loukugamage AU, Kunde
D: Vaginal route as the norm when planning hysterectomy for benign conditions: change in practice.Obstet Gynecol; 97:613-616.

Whiteman MK, Hillis SD, Jamieson DJ, Morrow B, Podgornik MN, Brett KM, Marchbanks PA, 2008: Inpatient hysterectomy surveillance in the United States, 2000-2004. Am J Obstet Gynecol; 198(1):34 e31-37.

Wu JM, Wechter ME, Geller EJ, Nguyen TV, Visco AG, 2007: Hysterectomy rates in the United States. Obstet Gynecol; 110(5):1091-1095. 


\title{
هل يسهل إستخدم عقار الجونادوتروبين هرمون اجوينستس في استئصال الرحم
}

\author{
عن طريق المهبل في الأرحام متوسطي الكُبْر؟
}

* محمد عبد الظاهر ، * أشرف معوض ، * محمد علي ،** و ائل مدكور ، *** حنا زهير

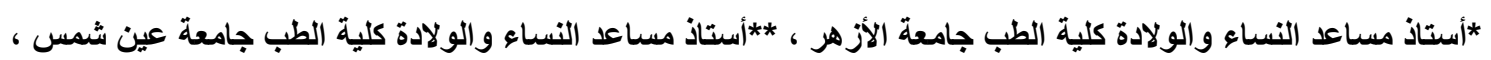

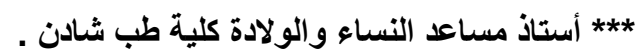

يعتبر استئصسال الرحم عن طريق المهبل الأسلوب المفضل لإزالة الرحم ولكن معظم أطباء أمراض النساء لا تزال تفضل

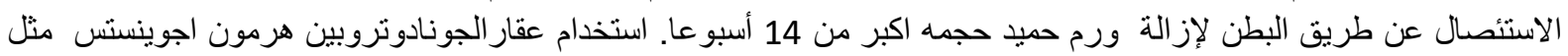

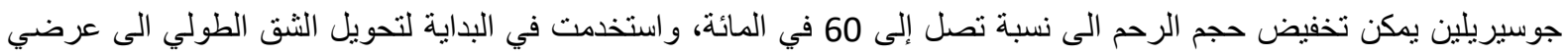
فى حالة استئصال الرحم عن طريق البطن, ونستخدهها الان لتحويل استئصال الرحم من طريق البطن الى طريق البـ المهبل محتملة بتخفيض حجم الرحم ليثبت أنه مفيد.

الهلف من الدراسة: لتقيبم فعالية استخدام عقار الجونادوتروبين هرمون اجوينستس قبل الجر احة للسيدات التي يعانين من تضخي

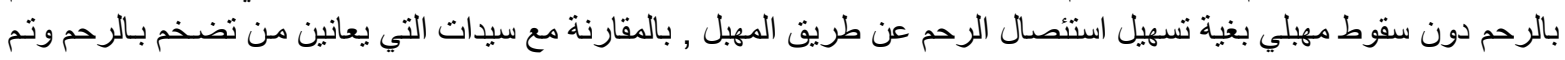
استئصال الرحم عن طريق البطن بنفس الداعي وهو زيادة الطمث.

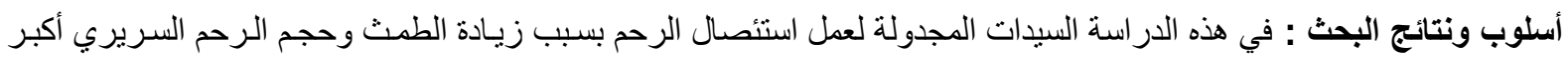

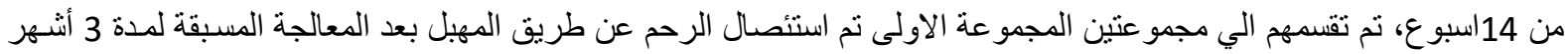

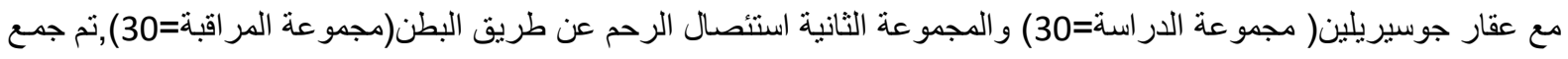

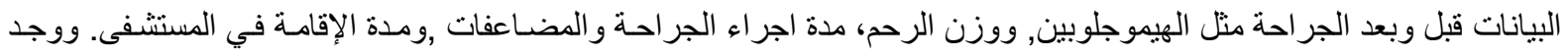

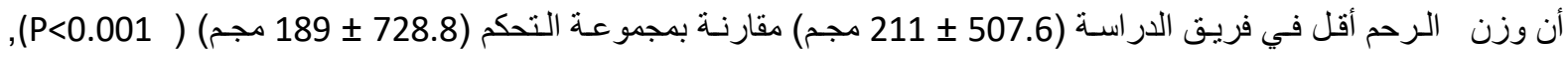

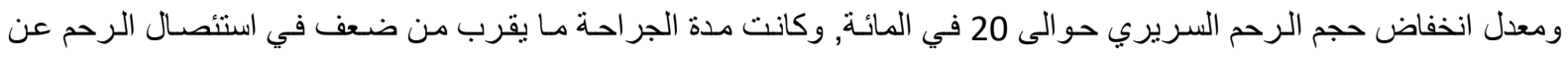

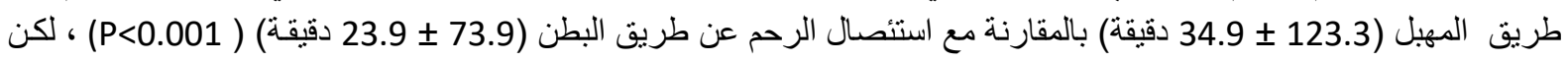

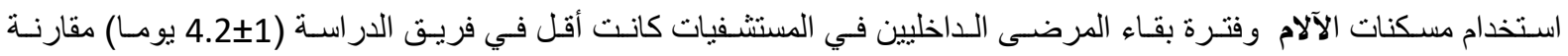

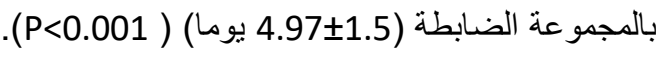

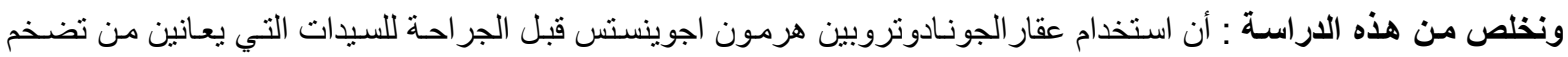

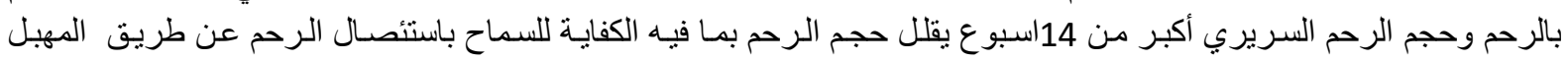

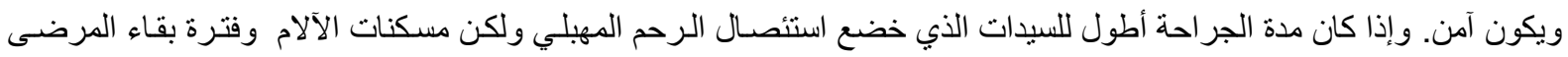
في المستشفيات كانت أقل, مع الخبرة، وقت الجر احة وفقدان الدم والمضاعفات لمكن أن تخفض بشكل كبير. 